\title{
Clinical evaluation of 4 types of microRNA in serum as biomarkers of esophageal squamous cell carcinoma
}

\author{
KAI WANG, DONGMEI CHEN, YUE MENG, JIANJUN XU and QINGYUN ZHANG
}

\author{
Key Laboratory of Carcinogenesis and Translational Research (Ministry of Education), \\ Department of Clinical Laboratory, Peking University Cancer Hospital and Institute, Beijing 100142, P.R. China
}

Received April 13, 2016; Accepted January 6, 2017

DOI: $10.3892 / \mathrm{ol} .2018 .8720$

\begin{abstract}
To the best of our knowledge, there is currently no specific biomarker for esophageal cancer used in clinical practice. However, studies consider that microRNAs (miRNAs/miRs) could have useful implications in clinical practice. The present study aimed to investigate the feasibility of using serum microRNAs as biomarkers for esophageal squamous cell carcinoma (ESCC). Using reverse transcription-quantitative polymerase chain reaction, the expression levels of serum miR-21, miR-25, miR-145 and miR-203 were detected in 31 untreated patients with ESCC (EC-UT), 35 inactive period patients with ESCC following treatment (EC-T), 33 patients with esophageal benign disease (benign) and 32 healthy donors (healthy). Furthermore, the ability of these microRNAs to function as biomarkers of ESCC alone and in combination were investigated. The expression levels of serum miR-21, miR-25 and miR-145 in EC-UT were significantly higher than in the other groups $(\mathrm{P}<0.001)$. High sensitivity and specificity were shown when miRNAs were used as biomarkers for ESCC, particularly miR-21 and the combination of miR-21 with miR-145. Comparing EC-UT with healthy, benign and EC-T groups, and a combined group (3 groups set as 1 negative control), the sensitivity and specificity of miR-21 were 71.0 and $96.9,74.2$ and $87.9,77.4$ and 82.9 , and 74.2 and $88.0 \%$, respectively. The combined sensitivity and specificity of miR-21 and miR-145 were 71.0 and 96.9, 90.9 and 72.7, 97.1 and 82.9, and 80.6 and $80.0 \%$, respectively. In conclusion, 3 types of miRNA (miR-21, miR-25 and miR-145) in serum could serve as potential biomarkers for ESCC. Furthermore, the expression level of miR-145 in serum
\end{abstract}

Correspondence to: Dr Qingyun Zhang, Key Laboratory of Carcinogenesis and Translational Research (Ministry of Education), Department of Clinical Laboratory, Peking University Cancer Hospital and Institute, 52 Fucheng Road, Haidian, Beijing 100142, P.R. China

E-mail: zhqy_208@163.com

Key words: serum microRNA, biomarker, esophageal squamous cell carcinoma, reverse transcription-quantitative polymerase chain reaction was upregulated, compared with the downregulation reported in previous studies in ESCC tissues and cells.

\section{Introduction}

Esophageal cancer (EC) is the seventh most common type of cancer and the sixth leading cause of cancer-related mortality in males worldwide (1). There were an estimated 455,800 new cases of EC and 400,200 mortalities as a result of EC in 2012 worldwide, with the highest rates being found in Eastern Asia, and in Eastern and Southern Africa (1). There are two main types of EC, squamous cell carcinoma (ESCC) and adenocarcinoma. In China, ESCC is rather common. It was previously reported that $88.84 \%$ of cases of EC were esophageal squamous cell carcinoma (2). Patients with EC are almost always diagnosed at advanced stages, and as a result the overall 5-year survival rate was $17.5 \%$ in 2004 globally (3). By contrast, the survival rate is $>80 \%$ if patients are diagnosed at an early stage when the disease is confined to the mucosa or submucosa and there is no metastasis to the lymph nodes (4). Routine tests, including endoscopic screening, imaging examinations and biopsies, have greatly improved the diagnosis of patients with EC; however, taking into account the traumatic or radiological injuries and the cost perspective, these are not feasible on a population scale (5-8). The identification of blood biomarkers could therefore constitute a significant advance in the diagnosis, prognosis and response to therapy for patients with EC (9).

MicroRNAs (miRNAs/miRs) are a class of single-stranded, well-conserved, small non-coding RNAs that are 20-24 nucleotides in length $(10,11)$. The latest miRBase (12) release (version 21, June 2014) contained 28,645 miRNA loci from 223 species, processed to produce 35,828 mature miRNAs. miRNAs have been shown to exhibit a promising role through their function as oncogenes or tumor suppressors (10,13-15). miRNAs possess the capacity to regulate target genes by binding to the 3'-untranslated region of target mRNA to repress their translation or regulate degradation $(16,17)$. Previously, it has been demonstrated that miRNAs are present in the circulating blood plasma, where they are protected from degradation in a stable, cell-free form by inclusion into lipid or lipoprotein complexes (18). Furthermore, miRNA profiles in the serum or plasma have been identified as having unique characteristic changes in certain types of solid tumor (19-21). 
These changes in miRNA profiles suggest that miRNAs could be ideal candidates as novel blood biomarkers in the clinical setting $(21,22)$.

\section{Materials and methods}

miRNAs. The expression profile of miRNAs in EC has been reported numerous times $(9,23,24)$. The present study chose several widely reported miRNAs from the published academic literature to investigate their expression levels in serum. The selected miRNAs in the present study were hsa-miR-21-5p (miR-21), hsa-miR-25-3p (miR-25), hsa-miR-145-5p (miR-145) and hsa-miR-203a-3p (miR-203) (Table I). The most widely reported miRNAs were selected from the three cited reviews and verified against the reports. Based on the different tumor-regulating functions expressed by the miRNA, the four miRNAs that were studied were finally selected. All searches were from English literature.

Serum collection. Whole blood samples were derived from patients at Peking University Cancer Hospital (Beijing, China) in January 2014. All diagnoses were confirmed using biopsy and endoscopic screening. The present study included 31 patients with untreated ESCC prior to definitive surgical intervention and/or adjuvant therapy (EC-UT group; 8 women and 23 men), 35 patients with ESCC following treatment (EC-T group; 8 surgery, 11 chemotherapy, 13 surgery and chemotherapy, and 3 radiotherapy; 9 women and 26 men) confirmed in an inactive period subsequent to outpatient review, and 33 patients with esophageal benign diseases (benign group; 17 reflux esophagitis, 12 gastroesophageal reflux disease and 4 erosive esophagitis; 12 women and 21 men). Disease staging was performed in accordance to the American Joint Committee on Cancer/Union for International Cancer Control stage classification (7th edition) (25). The characteristics of the subjects are summarized in Table II. A total of 32 serum samples from healthy individuals (healthy group; 13 women and 19 men) were used as controls. None of them had been previously diagnosed with malignancy. Ethical permission and informed consent was obtained for the use of all samples. Blood samples were centrifuged at $900 \mathrm{x} \mathrm{g}$ for $10 \mathrm{~min}$ at $4{ }^{\circ} \mathrm{C}$ to completely remove all cellular components, and the supernatant (serum) was collected. The sera were immediately frozen at $-80^{\circ} \mathrm{C}$ until use.

All patients and healthy individuals provided informed consent. All study procedures were performed in accordance with the Helsinki Declaration, and the study was approved by the Ethics Committee of Peking University Cancer Hospital and Institute (Beijing, China).

RNA isolation. RNA was extracted from $350 \mu \mathrm{l}$ serum using TRIzol LS Reagent (Ambion; Thermo Fisher Scientific, Inc., Waltham, MA, USA) according to the manufacturer's protocol. Briefly, $1.0 \mathrm{ml}$ TRIzol LS reagent was added to the serum sample, and the mixture was incubated for $5 \mathrm{~min}$ at room temperature. Next, $200 \mu \mathrm{l}$ chloroform was added and the tube was vigorously agitated for $15 \mathrm{sec}$, and incubated at room temperature for $15 \mathrm{~min}$. Subsequent to centrifugation at $12,000 \times \mathrm{g}$ for $15 \mathrm{~min}$ at $4^{\circ} \mathrm{C}$, the supernatant was transferred to a fresh tube, and an equal volume of isopropanol was added. Following incubation at $-20^{\circ} \mathrm{C}$ for $30 \mathrm{~min}$, the mixture
Table I. Sequences of miRNAs and internal reference.

\begin{tabular}{ll}
\hline miRNA/gene & \multicolumn{1}{c}{ Sequence } \\
\hline miR-21 & UAGCUUAUCAGACUGAUGUUGA \\
miR-25 & CAUUGCACUUGUCUCGGUCUGA \\
miR-145 & GUCCAGUUUUCCCAGGAAUCCCU \\
miR-203 & GUGAAAUGUUUAGGACCACUAG \\
U6 & GTGCTCGCTTCGGCAGCACATATA \\
& CTAAAATTGGAACGATACAGAGAA \\
& GATTAGCATGGCCCCTGCGCAAGG \\
& ATGACACGCAAATTCGTGAAGCGT \\
& TCCATATTTT
\end{tabular}

miRNA/miR, microRNA; U6, RNU6-1.

was centrifuged at $12,000 \mathrm{xg}$ for $10 \mathrm{~min}$ at $4^{\circ} \mathrm{C}$ to discard the supernatant, and the RNA pellet was washed with $75 \%$ ethanol. Subsequent to the removal of ethanol by centrifugation at $7,500 \mathrm{x}$ g for $5 \mathrm{~min}$ at $4^{\circ} \mathrm{C}$, RNA was air dried for $10 \mathrm{~min}$ and then dissolved in $50 \mu \mathrm{l}$ RNase-free water and stored at $-80^{\circ} \mathrm{C}$ until further processing.

Reverse transcription-quantitative polymerase chain reaction $(R T-q P C R)$ of miRNAs. TaqMan ${ }^{\circledR}$ MicroRNA Reverse Transcription kit (Applied Biosystems; Thermo Fisher Scientific, Inc.) was used to perform $15-\mu 1$ reverse transcription reactions that contained $5 \mu \mathrm{l}$ purified serum RNA, $0.15 \mu 1100 \mathrm{mM}$ dNTPs (with dTTP), $1 \mu 150 \mathrm{U} / \mu 1$ MultiScribe ${ }^{\mathrm{TM}}$ Reverse Transcriptase, $1.5 \mu \mathrm{l} 10 \mathrm{X}$ reverse transcription buffer, and $0.19 \mu \mathrm{l} 20 \mathrm{U} / \mu \mathrm{l}$ RNase inhibitor, $4.16 \mu 1$ nuclease-free water and $3 \mu \mathrm{l}$ of $5 \mathrm{X}$ stem-loop RT primer (TaqMan ${ }^{\circledR}$ MicroRNA Assays; Thermo Fisher Scientific, Inc.). The mixture was incubated at $16^{\circ} \mathrm{C}$ for $30 \mathrm{~min}, 42^{\circ} \mathrm{C}$ for $30 \mathrm{~min}$ and $85^{\circ} \mathrm{C}$ for $5 \mathrm{~min}$. RNase-free water was used as reverse transcription negative controls.

Subsequently, real-time quantification was performed using the LightCycler 480 Real-Time PCR system (Roche Molecular Diagnostics, Pleasanton, CA, USA) with TaqMan ${ }^{\circledR}$ Universal PCR Master Mix II, no UNG (Applied Biosystems; Thermo Fisher Scientific, Inc.). The 15- $\mu$ l PCR contained 4.5 $\mu 1 \mathrm{RT}$ product, $7.5 \mu 12 \mathrm{X}$ TaqMan ${ }^{\circledR}$ Universal PCR Master Mix II, $0.75 \mu 120 \mathrm{X}$ primer and probe (TaqMan ${ }^{\circledR}$ MicroRNA assays; Thermo Fisher Scientific, Inc.) and $2.25 \mu 1$ nuclease-free water. The reactions were incubated in a 96 -well optical plate at $95^{\circ} \mathrm{C}$ for $10 \mathrm{~min}$, followed by 50 cycles of $95^{\circ} \mathrm{C}$ for $15 \mathrm{sec}$ and $60^{\circ} \mathrm{C}$ for $1 \mathrm{~min}$. All reactions were run in triplicate, including blank controls without complementary DNA (cDNA).

Relative quantification of serum miRNAs. The cycle threshold (Cq) was defined as the number of cycles required for the fluorescent signal to cross the threshold in qPCR. Following reactions, the $\mathrm{Cq}$ data were determined using default threshold settings, and the means of the $\mathrm{Cq}$ were obtained from the triplicate PCRs. The purpose of the internal reference gene is to normalize the PCRs for the amount of RNA added to the reactions. As there is no current consensus on the use of house-keeping genes or miRNAs for qPCR analysis, based on previously published results, the present study used 
Table II. Clinical characteristics of serum samples.

\begin{tabular}{lcccc}
\hline Characteristic & Healthy & Benign & EC-UT & EC-T \\
\hline $\begin{array}{l}\text { No. of patients } \\
\text { Age, years }\end{array}$ & 32 & 33 & 31 & 35 \\
Mean (range) & $53(34-72)$ & $51(27-83)$ & $58(44-75)$ & $60(48-76)$ \\
$<55$ & 19 & 17 & 11 & 10 \\
$\geq 55$ & 13 & 16 & 20 & 25 \\
Sex & & & 21 & 24 \\
Male & 19 & 19 & 10 & 11 \\
Female & 13 & 14 & 9 & 11 \\
Clinical stage & & & 22 & 24 \\
I-II & - & - & 0 & 8 \\
III-IV & & & 0 & 11 \\
Treatment & 0 & 0 & 0 & 13 \\
Surgery & 0 & 0 & 0 & 3 \\
Chemotherapy & 0 & 0 & & \\
Surgery and chemotherapy & 0 & 0 & & \\
Radiotherapy & & & & \\
\hline
\end{tabular}

EC-UT, untreated patients with esophageal squamous cell carcinoma; EC-T, patients with esophageal squamous cell carcinoma following treatment.

RNU6-1 (U6) as the internal reference for quantification (Table I) $(26,27)$. The relative amount of miRNA was normalized to U6. The fold-change for miRNAs from 4 groups of samples relative to the calibrator was calculated using the $2^{-\Delta \Delta \mathrm{Cq}}$ method where $\Delta \Delta \mathrm{Cq}=\Delta \mathrm{Cq}$ (sample) $-\Delta \mathrm{Cq}$ (calibrator) and $\Delta \mathrm{Cq}=\mathrm{Cq}$ (miRNA)-Cq (U6) (28).

Choice of calibrator. Firstly, a serum pool of 50 healthy donors was packed into 500- $\mu$ l Eppendorf tubes and stored at $-80^{\circ} \mathrm{C}(20)$. One tube was then taken as a candidate for the calibrator sample (termed 'serum pool'). EC-109 is a type of ESCC cell line cultured in vitro, which was provided by the Cell Resource Center, Institute of Biomedical Science, Chinese Academy of Medical Sciences/Peking Union Medical College (Beijing, China). Following recovery, EC-109 cells were grown in RPMI-1640 medium (Gibco; Thermo Fisher Scientific, Inc.) supplemented with $10 \%$ fetal bovine serum (Gibco; Thermo Fisher Scientific, Inc.) and $100 \mathrm{U} / \mathrm{ml}$ penicillin-streptomycin at $37^{\circ} \mathrm{C}$ in a humidified atmosphere containing $5 \% \mathrm{CO}_{2}$. The cells were cultured for 8 successive generations, and collected from the fourth to the eighth generation together. Cells were then packed into $1 \mathrm{ml}$ tubes and stored in liquid nitrogen, and this was taken as another candidate for the calibrator sample (EC-109). Secondly, 15 serum samples were chosen from patients with ESCC at random, and the expression levels of serum miRNAs were detected and calculated in accordance with the aforementioned process using two candidate calibrators (serum pool and EC-109). Next, one calibrator was selected by comparing the two groups of data.

Amplification efficiency and Pearson's correlation coefficient. Briefly, a 10-fold dilution series of cDNA containing the tested miRNAs and the reference U6 gene were used as the template for qPCR to generate a plot of log concentration of the tested miRNA at different dilutions vs. the corresponding $\mathrm{Cq}$ (29). The slope of the linear plot is defined as $-(1 / \log E)$, where $E$ is the amplification efficiency, and its value should approach 2 if the efficiency reaches the maximum $(28,29)$.

Correlation is a technique for investigating the association between two quantitative, continuous variables $(21,30)$. The nearer the scatter of points is to a straight line, the higher the strength of association between the variables $(21,30)$. The Pearson's correlation coefficient $(\mathrm{R})$ may take any value between -1 and $+1(20,21)$.

Statistical analysis. Statistical analyses were performed using SPSS 19.0 software (IBM SPSS, Armonk, NY, USA). Data shown are presented as the mean \pm standard error, and the differences between miRNA expression levels and groups were determined by non-parametric tests (Kruskal Wallis test). Receiver operating characteristic (ROC) curves and the area under the ROC curve were used to assess the feasibility of using serum miRNAs as a diagnostic tool in discriminating patients with ESCC from negative controls (31). The present study used the Youden index for the identification of the optimal cut-off point $(32,33)$. All $\mathrm{P}$-values were two-sided, and $\mathrm{P}<0.05$ was considered to indicate a statistically significant difference.

\section{Results}

qPCR amplification efficiency and linearity. The qPCR amplification efficiencies (E) in the exponential phase were calculated according to the following equation (28):

$$
\mathrm{E}=10^{-\left(\frac{1}{\text { slope }}\right)}
$$



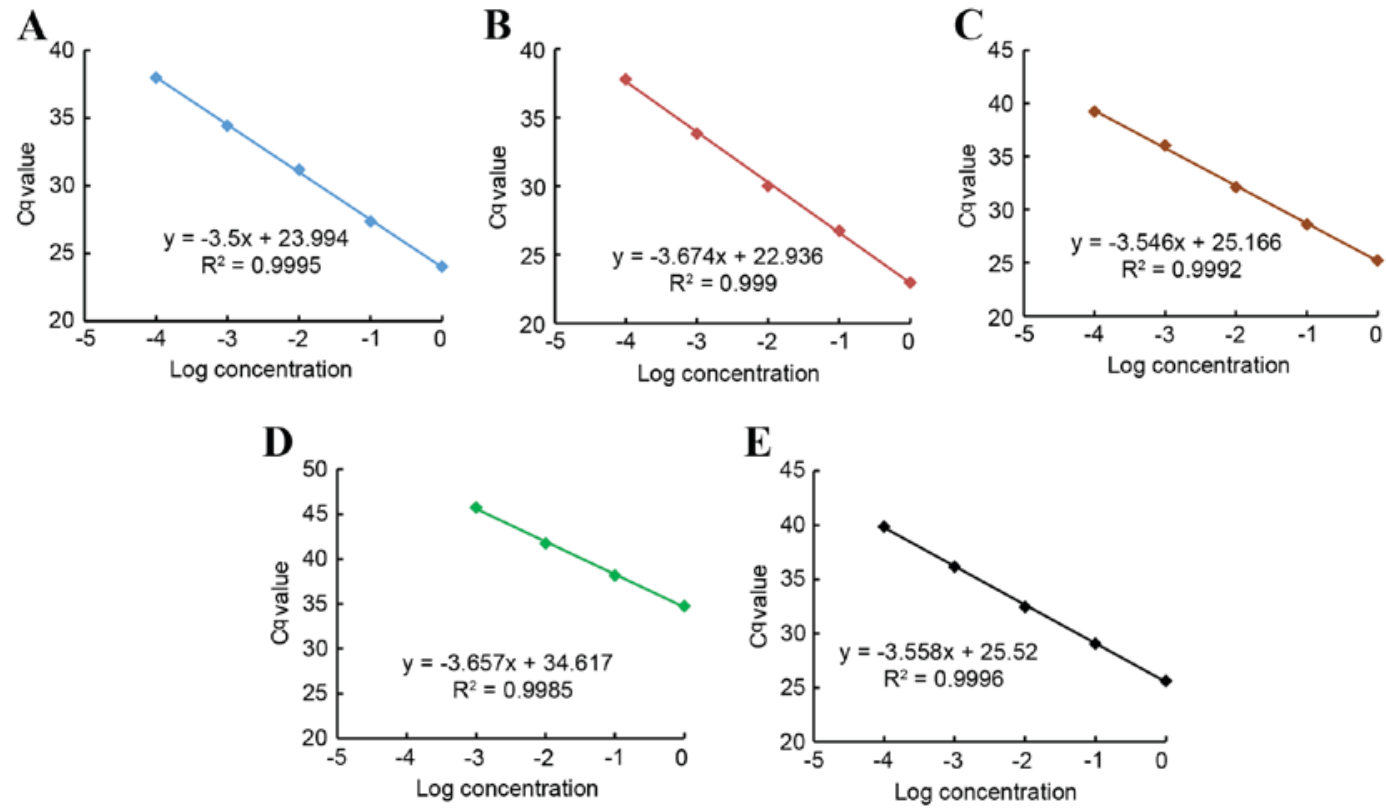

Figure 1. Scattered plots of log concentration of miRNAs and U6 at different dilutions vs. the corresponding Cq. The 10-fold serial dilutions of miRNAs and U6 were used to generate the scatter plots. The $\mathrm{Cq}$ value was so close to 50 that the point of 10,000 times dilution of miR-203 was abandoned. (A) miR-21; (B) miR-25; (C) miR-145; (D) miR-203; and (E) U6. miRNA, microRNA; U6, RNU6-1.

The results revealed that the amplification efficiencies of miRNAs and U6 (miR-21, 1.93; miR-25, 1.87; miR-145, 1.91; miR-203, 1.88; and U6, 1.91) approached the maximum value, and the difference among them was $<5 \%$. The best fit line also demonstrated the strong linearity between the input of miRNAs and the $\mathrm{Cq}$ values for RT-qPCR, and also between the input of U6 and the Cq values (Pearson's correlation coefficient, r>0.99) (Fig. 1).

Intra- and inter-assay variation. To confirm the accuracy and reproducibility of qPCR, the intra-assay precision was determined in 6 repeats within one lightcycler run. Inter-assay variation was investigated in all experimental runs performed on different days. Variability of target genes, miRNAs and U6, was low in inter-test experiments (miR-21, 0.22\%; miR-25, $0.21 \%$; miR-145, 0.21\%; miR-203, 0.64\%; and U6, $0.26 \%$, respectively) and in intra-test experiments (miR-21, 1.55\%; miR-25, 1.61\%; miR-145, 1.92\%; miR-203, 1.76\%; and U6, $1.39 \%$, respectively) (Table III). These data confirmed that the present study had good repeatability and reliability.

Comparison of calibrators. The $2^{-\Delta \Delta \mathrm{Cq}}$ method ensured that data from two different candidates for calibration had the same coefficient of variation (28). Therefore, the standard deviation and range were more suitable to evaluate them. The data is shown in Table IV.

The results revealed that the serum pool exhibited significantly smaller standard deviations and ranges in 3 miRNAs and similar values in another miRNA, so the serum pool was selected as the calibrator.

Expression levels of serum miRNAs. The present study first analyzed the expression of 4 miRNAs, respectively, in the 4 groups, and compared the results with the expression of the different miRNAs among these groups. The mean levels of serum miR-21, miR-25 and miR-145 in EC-UT were significantly higher than in the other groups (all $\mathrm{P}<0.001$; Fig. 2). However, the level of serum miR-203 in EC-UT was higher than in the benign and EC-T groups, but lower than in the healthy group (all $\mathrm{P}>0.05$; Fig. 2). Subsequently, the present study evaluated whether there was a correlation between the level of miRNA and the clinical characteristics of the samples. The results revealed that expression of all 4 miRNAs exhibited no statistical correlation with sex, age or clinical stage (all $\mathrm{P}>0.05$; data not shown).

Evaluation of each serum miRNA as a potential marker. The present study performed ROC curve analyses to evaluate whether the serum miRNAs can be used as potential diagnostic markers for EC. Firstly, expression levels of 4 miRNAs were compared between the EC-UT group and the healthy group. The ROC curve areas were 0.88 (95\% CI, 0.80-0.97) for miR-21, 0.72 (95\% CI, 0.59-0.84) for miR-25, 0.83 (95\% CI, 0.73-0.94) for miR-145 and 0.51 (95\% CI, 0.37-0.66) for miR-203. At the cut-off values of $4.37,1.20,1.16$ and 6.32 , sensitivity and specificity in EC diagnosis were 71.0 and $96.9 \%$ for miR-21, 71.0 and $68.8 \%$ for miR-25, 90.3 and $68.8 \%$ for miR-145, and 54.8 and $62.5 \%$ for miR-203 (Fig. 3A). It was revealed that the levels of serum miR-21, miR-25 and miR-145 were potential markers for discriminating patients with EC-UT from healthy donors. As there was no significant difference in the expression level of serum miR-203 among different groups, miR-203 was no longer considered as a potential marker.

Secondly, the EC-UT group and the benign group were compared. The ROC curve areas were 0.88 (95\% CI, 0.80-0.96) for miR-21, 0.72 (95\% CI, 0.59-0.84) for miR-25, 0.71 (95\% CI, 0.58-0.84) for miR-145 and 0.54 (95\% CI, 0.38-0.69) for miR-203. At the cut-off values of 3.68, 0.79, 2.79 and 13.75, sensitivity and specificity were 74.2 and $87.9 \%$ for miR-21, 83.9 and $51.5 \%$ for miR-25, 67.7 and $75.8 \%$ for miR-145, and 41.9 and $87.9 \%$ for miR-203 (Fig. 3B). Therefore, the levels of 3 serum miRNAs 
Table III. Intra-assay and inter-assay variation of quantitative polymerase chain reaction.

\begin{tabular}{|c|c|c|c|c|c|}
\hline Assay statistics & miR-21 & miR-25 & miR-145 & miR-203 & U6 \\
\hline \multicolumn{6}{|l|}{ Inter-assay } \\
\hline Mean \pm SE & $23.986 \pm 0.019$ & $23.458 \pm 0.017$ & $25.201 \pm 0.019$ & $35.520 \pm 0.080$ & $26.281 \pm 0.024$ \\
\hline $\mathrm{CV}, \%$ & 0.22 & 0.21 & 0.21 & 0.64 & 0.26 \\
\hline \multicolumn{6}{|l|}{ Intra-assay } \\
\hline Mean \pm SE & $24.419 \pm 0.143$ & $22.998 \pm 0.140$ & $25.713 \pm 0.187$ & $34.791 \pm 0.232$ & $25.829 \pm 0.136$ \\
\hline $\mathrm{CV}, \%$ & 1.55 & 1.61 & 1.92 & 1.76 & 1.39 \\
\hline
\end{tabular}

$\mathrm{SE}$, standard error; $\mathrm{CV}$, coefficient of variation.

Table IV. Discrete description of the two calibrators.

\begin{tabular}{|c|c|c|c|c|c|c|}
\hline Calibrators & Minimum & Maximum & Mean & Range & Standard deviation & $\mathrm{CV}, \%$ \\
\hline \multicolumn{7}{|l|}{ EC-109 } \\
\hline miR-21 & 16.00 & 831.75 & 184.08 & 815.75 & 237.22 & 128.87 \\
\hline $\operatorname{miR}-25$ & 1871.53 & 33923.56 & 11261.79 & 32052.03 & 8770.17 & 77.88 \\
\hline $\operatorname{miR}-145$ & 87076.75 & 2511294.86 & 771032.59 & 2424218.11 & 680663.2 & 88.28 \\
\hline miR-203 & 0.08 & 14.12 & 4.20 & 14.05 & 4.69 & 111.79 \\
\hline \multicolumn{7}{|l|}{ Serum pool } \\
\hline $\operatorname{miR}-21$ & 0.76 & 39.67 & 8.78 & 38.91 & 11.31 & 128.87 \\
\hline $\operatorname{miR}-25$ & 0.53 & 9.58 & 3.18 & 9.05 & 2.48 & 77.88 \\
\hline $\operatorname{miR}-145$ & 0.44 & 12.55 & 3.85 & 12.12 & 3.40 & 88.28 \\
\hline miR-203 & 0.18 & 32.67 & 9.71 & 32.50 & 10.85 & 111.79 \\
\hline
\end{tabular}

$\mathrm{CV}$, coefficient of variation.
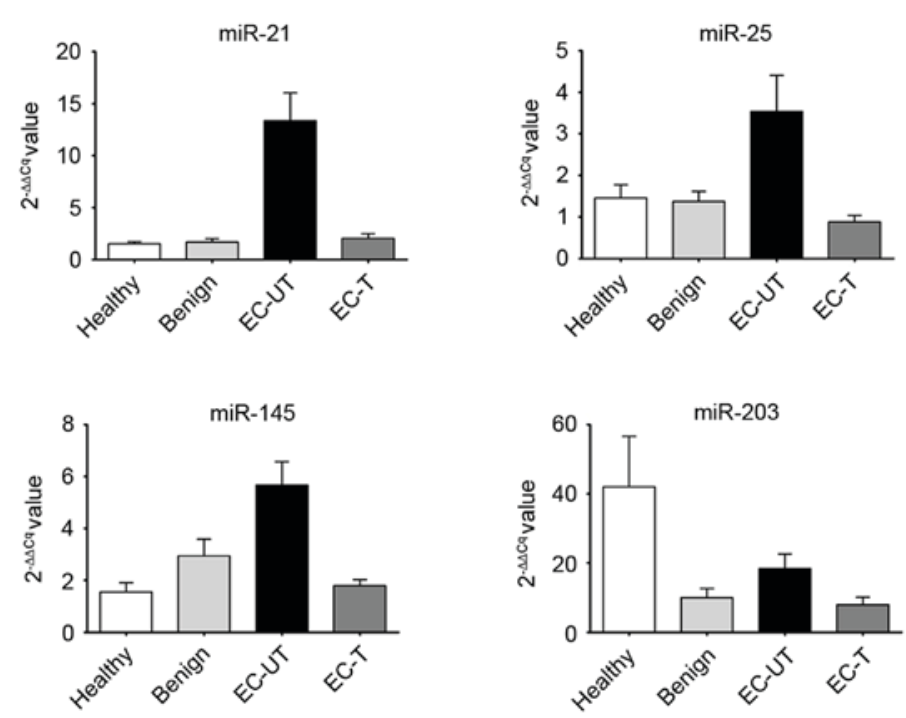

Figure 2. Column charts of serum levels of 4 miRNAs. Values shown were normalized to U6. Comparison of serum miRNAs levels in 4 groups. The mean levels of serum miR-21, miR-25 and miR-145 in EC-UT were significantly higher than in other groups (all $\mathrm{P}<0.001)$. The mean level of serum miR-203 in EC-UT was higher than in the benign and EC-T groups, and lower than in the healthy group (all P>0.05). No significant difference was identified between the expression levels of 4 miRNAs among the healthy, benign and EC-T groups (all P>0.05). miRNA, microRNA; U6, RNU6-1; ESCC, esophageal squamous cell carcinoma; EC-UT, untreated patients with ESCC; EC-T, patients with ESCC following treatment.

(miR-21, miR-25 and miR-145) could serve as potential markers to discriminate patients with EC-UT from benign patients.
To additionally discriminate the EC-UT group from the EC-T group, the ROC curve areas were 0.85 (95\% CI, 

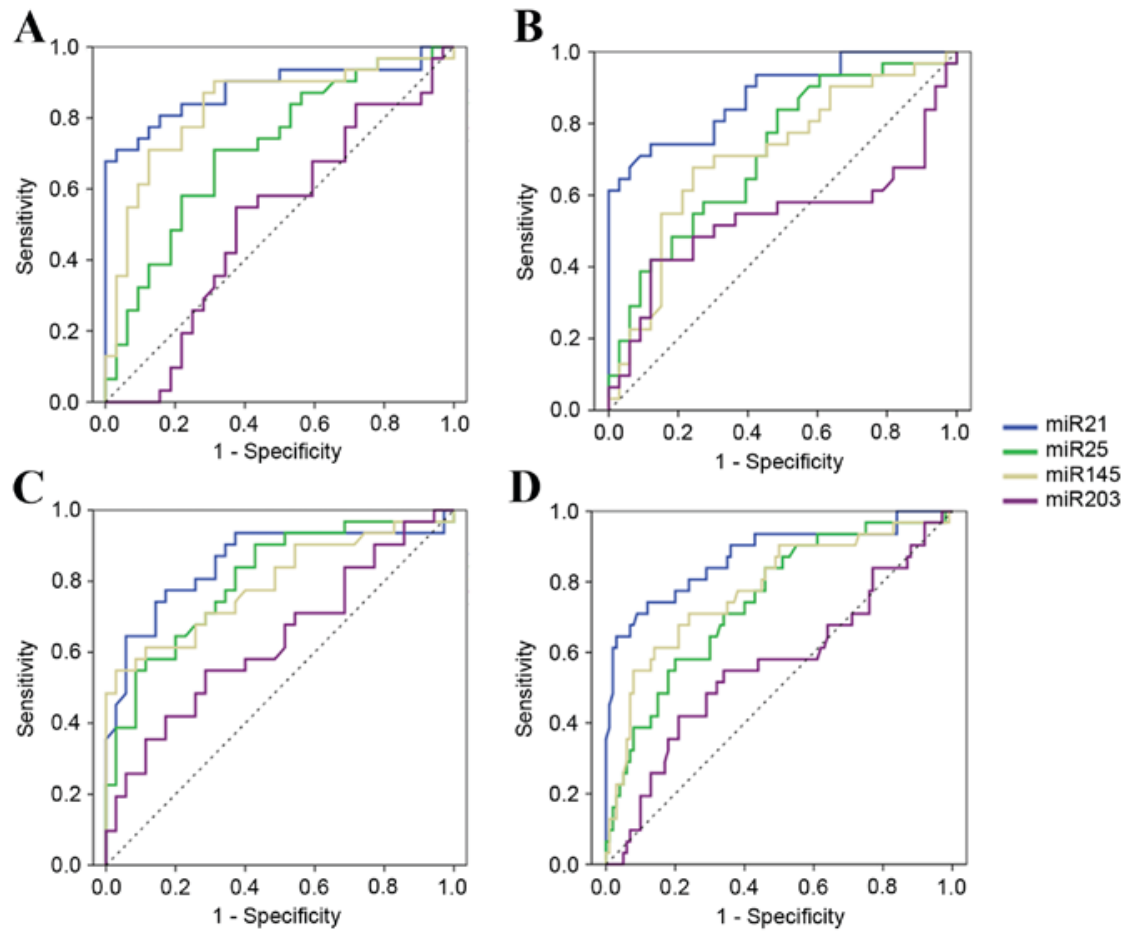

Figure 3. Receiver-operator characteristic curves of the miRNAs for discriminating EC patients from other groups. (A) EC-UT vs. healthy; (B) EC-UT vs. benign; (C) EC-UT vs. EC-T; and (D) EC-UT vs. all others. miRNA, microRNA; EC, esophageal cancer; ESCC, esophageal squamous cell carcinoma; EC-UT, untreated patients with ESCC; EC-T, patients with ESCC following treatment; ESCC, esophageal squamous cell carcinoma.

0.75-0.95) for miR-21, 0.80 (95\% CI, 0.70-0.91) for miR-25, 0.79 (95\% CI, 0.68-0.91) for miR-145 and 0.63 (95\% CI, 0.50-0.77) for miR-203. At the cut-off values of 2.77, 0.64 , 4.61 and 6.92 , sensitivity and specificity were 77.4 and $82.9 \%$ for miR-21, 90.3 and $57.1 \%$ for $\mathrm{miR}-25,54.8$ and $97.1 \%$ for miR-145, and 54.8 and $71.4 \%$ for miR-203 (Fig. 3C).

These results suggest that serum miR-21, miR-25 and miR-145 could be promising biomarkers for diagnosis, differential diagnosis between benign disease and ESCC, and evaluation of therapeutic efficiency.

In addition, the present study also analyzed the expression of the 4 miRNAs among healthy, benign and EC-T groups, and identified no significant difference (all $\mathrm{P}>0.05$; Fig. 2). Therefore, these 3 groups were set as one negative control (termed 'all others'), and discriminated from EC-UT patients, with ROC curve areas of 0.87 (95\% CI, 0.79-0.95) for miR-21, 0.75 (95\% CI, 0.65-0.85) for miR-25, 0.78 (95\% CI, 0.68-0.88) for miR-145 and 0.56 (95\% CI, 0.44-0.69) for miR-203, respectively. At the cut-off values of 3.68, 1.98, 3.58 and 13.749, sensitivity and specificity were 74.2 and $88.0 \%$ for miR-21, 58.1 and $80.0 \%$ for miR-25, 61.3 and $86.0 \%$ for miR-145, and 41.9 and $79.0 \%$ for miR-203 (Fig. 3D).

Therefore, the results also suggest that serum miR-21, miR-25 and miR-145 could be potential biomarkers of ESCC for population screening.

Evaluation of combined application of serum miRNAs as potential markers. The 3 selected serum miRNAs (miR-21, miR-25 and miR-145) were divided into 4 different combinations, and then evaluated to determine whether each of the new combinations could be used as a single tumor marker for discriminating EC-UT patients from other groups by using two methods (series connection and parallel connection). The 4 combinations were as follows: miR-21 and miR-25; miR-21 and miR-145; miR-25 and miR-145; and miR-21, miR-25 and miR-145, respectively. First, in terms of the series connection method, when all serum miRNAs of one sample were in excess of their cut-off values, this was defined as a positive sample; on the contrary, this was defined as negative in any other statuses. Subsequently, in terms of the parallel connection method, the sample was defined as positive if any serum miRNA of one sample was in excess of its cut-off value, while others were defined as negative. Sensitivity and specificity are shown in Table V. The results revealed that sensitivity and specificity of certain combinations, particularly miR-21 and miR-145, were significantly high. When comparing EC-UT with the healthy, benign, EC-T and all others groups, the sensitivity and specificity of miR-21 and miR-145 were 71.0 and $96.9 \%$ (series connection), 90.9 and $72.7 \%$ (parallel connection), 97.1 and $82.9 \%$ (parallel connection), and 80.6 and $80.0 \%$ (parallel connection), respectively.

\section{Discussion}

The study for novel tumor markers is a rapidly growing area, however, a gap exists between laboratory studies and clinical practice. With additional investigation, it is generally considered that miRNAs could provide an important breakthrough in the study of tumor markers in clinical practice.

Specificity and reliability in the present study were guaranteed with the use of a stem-loop RT primer and TaqMan probe. Due to the advantage of the high specificity of the stem-loop RT primer, it was used to perform the reverse transcription of miRNA $(34,35)$. The TaqMan probe was utilized in the PCR 
process since the accuracy of TaqMan RT-qPCR is significantly higher than when using SYBR-Green in PCR analysis $(36,37)$.

The serum pool was chosen as the calibrator rather than EC-109 for two reasons. First, the data calculated using the $2^{-\Delta \Delta C q}$ relative quantitative method was used to calculate the miRNAs expression levels relative to the calibrator (28). In theory, the value obtained can be used for the comparison of miRNA levels among different groups, if utilizing the identical calibrator. When EC-109 is used as the calibrator, the value represents the increase or decrease of miRNAs between serum and ESCC cells, which is more convenient to compare the expression levels of miRNAs between the present study and in tissues and/or cells reported previously. However, in contrast to EC-109, the discrete tendency of the data when using the serum pool as the calibrator was statistically lower. Secondly, when the serum pool was set as the calibrator, miRNAs in the calibrator and sample serum were all derived from the whole blood, therefore, the inherent interference factors of the calibrator and sample serum in the experimental process, including protoheme, are also similar. The experimental error of serum miRNAs can be corrected with the use of the $2^{-\Delta \Delta C q}$ method by calibration.

The present study highlighted the potential application of serum miRNAs as biomarkers of ESCC in the clinical practice. There are currently no specific tumor markers for EC in clinical practice; therefore, it is hoped that the routine tumor markers, including carcinoembryonic antigens and novel miRNAs markers, were detected in only one tube of serum sample. According to the requirement of experimental procedure and the limitations of clinical application, the present study determined that the number of selected miRNAs is four. By performing the $2^{-\Delta \Delta \mathrm{Cq}}$ method to calculate the fold change as the expression of 4 types of miRNAs among 4 separate groups (EC-UT, EC-T, benign and healthy), the present study systematically evaluated the feasibility of these miRNAs as tumor markers for ESCC. The present results suggested that serum miR-21, miR-25 and miR-145, particularly miR-21, could be ideal tumor markers with high and stable sensitivity and specificity for diagnostic and prognostic monitoring. Additionally, with series connection or parallel connection methods, these 3 miRNAs were divided into 4 different combinations with 2 or 3 miRNAs; consequently, the sensitivity and/or specificity of combinations, particularly miR-21 and miR-25 will be further improved.

miR-145, as a tumor suppressor, differing from miR-21 and miR-25 with their oncogenic function $(20,38-42)$, is significantly downregulated in ESCC tissues, which can inhibit cell motility in squamous cell carcinoma-derived cell lines $(23,43)$. However, the present study identified that there was a certain degree of upregulation in the expression of peripheral blood serum miR-145 in patients with ESCC. A similar trend was also identified in the detection of miR-203, which inhibits cell proliferation in squamous cell carcinoma-derived cell lines $(44,45)$. Serum miR-203 in EC-UT patients was much higher than that in EC-T and benign patients, but lower than that in healthy patients, although the difference was not significant. For this phenomenon, first of all, it was assumed that it may be associated with circulating tumor cells (CTCs). Subsequent to blood flowing through the solid tumor, a large number of CTCs migrate into the blood (46). For instance, the quantity of CTCs detected in the pulmonary venous blood of patients with primary lung cancer was up to 10,034 per 
$7.5 \mathrm{ml}$ blood (mean, 1,195) (47). By contrast, the quantity of CTCs in the peripheral blood is almost always zero, although occasionally it is $1-3$ cells per $7.5 \mathrm{ml}(47,48)$. This reduction of CTCs in the blood circulation may be a result of the cells being broken due to various reasons. The cells may be broken, however, the tumor suppressor miRNAs in the cells do not disappear; instead, they enter the blood.

In other words, although the amount of tumor suppressor miRNAs in a single cell is reduced, the number of CTCs is significantly increased, which ultimately results in an increase of serum tumor suppressor miRNAs. Secondly, the present study also assumed that the degree of downregulation of miRNAs in a single tumor cell may affect the abundance of these serum miRNAs, and so differences exist between miR-145 and miR-203, although the two are tumor suppressors (20,38-42). Furthermore, the number of tumor cells migrating into the blood varies among different patients, which also affects the separation degree of expression of miRNAs in the peripheral blood serum and in individual cells. Finally, miRNA has the advantage of having a stable existence and the ability to reflect the activity of genes compared with mRNA, protein and DNA. Therefore, it was assumed that miRNA could more accurately reflect the situation of the tumor cells in the blood circulatory system, and could therefore be more efficiently performed to evaluate tumor metastasis with the quantity of peripheral blood CTCs. However, additional studies are required to prove this assumption.

Inevitably, there were limitations to the present study. First, long-term follow-up data was not collected. The size of samples was also relatively small, and a larger sample size is required to have a beneficial effect on the discovery of the differences of serum miRNAs among clinical stages (49). The selected 4 types of miRNA with a similar dysregulation status may also exist in other tumors at the same time $(24,38,39,42,44)$. Therefore, if the miRNAs selected are regulatory miRNAs of definite driver genes of EC, the study of these miRNAs and driver genes may improve the discriminability of ESCC with other cancer types $(15,50)$. Nevertheless, the feature of multiple-targets of miRNAs may remain an obstacle for finding this type of miRNA and driver genes with target associations $(9,14,51)$.

The present study revealed that 3 miRNAs (miR-21, miR-25 and miR-145) in serum had higher expression levels in untreated patients with ESCC compared with healthy patients, and had the ability to distinguish, to a certain degree, untreated patients with ESCC from negative controls. Additional studies are required to validate whether these or other miRNAs may be utilized clinically as screening biomarkers for the early detection, prognosis and evaluation of the therapeutic efficiency of ESCC. Additional improvements are also required to apply the results of fundamental studies such as these to routine clinical applications.

\section{Acknowledgements}

Not applicable.

\section{Funding}

The present study was supported by grants from the National High Technology Research and Development Program of China (863 program; grant no. 2012AA02A204-B04).

\section{Availability of data and materials}

All data generated or analyzed during the present study are included in this published article.

\section{Authors' contributions}

QZ and KW conceived and designed the study. KW, DC, YM and JX performed the experiments. KW and DC wrote the paper. QZ and KW reviewed and edited the manuscript. All authors read and approved the manuscript and agreed to be accountable for all aspects of the research in ensuring that the accuracy or integrity of any part of the study was appropriately investigated and resolved.

\section{Ethics approval and consent to participate}

The present study was approved by the Ethics Committee of Peking University Cancer Hospital and Institute (Beijing, China).

\section{Consent for publication}

The patients have provided written informed consent for the publication of associated data. All identifying information has been removed.

\section{Competing interests}

The authors declare that they have no competing interests.

\section{References}

1. Torre LA, Bray F, Siegel RL, Ferlay J, Lortet-Tieulent J and Jemal A: Global cancer statistics, 2012. CA Cancer J Clin 65: 87-108, 2015.

2. Zeng H, Zheng R, Zhang S, Zuo T, Xia C, Zou X and Chen W: Esophageal cancer statistics in China, 2011: Estimates based on 177 cancer registries. Thorac Cancer 7: 232-237, 2016.

3. Howlader N, Noone AM, Krapcho M, Garshell J, Miller D, Altekruse SF, Kosary CL, Yu M, Ruhl J, Tatalovich Z, et al: (eds): SEER Cancer Statistics Review, 1975-2011. In. 2014; National Cancer Institute. Bethesda, MD, http://seer.cancer. gov/csr/1975_2011/, based on November 2013 SEER data submission, posted to the SEER web site, Accessed April, 2014.

4. Barbour AP, Jones M, Brown I, Gotley DC, Martin I, Thomas J, Clouston A and Smithers BM: Risk stratification for early esophageal adenocarcinoma: Analysis of lymphatic spread and prognostic factors. Ann Surg Oncol 17: 2494-2502, 2010.

5. Ajani JA, D'Amico TA, Almhanna K, Bentrem DJ, Besh S, Chao J, Das P, Denlinger C, Fanta P, Fuchs CS, et al: Esophageal and esophagogastric junction cancers, version 1.2015. J Nati Compr Canc Netw 13: 194-227, 2015.

6. Zuccaro G Jr, Rice TW, Goldblum J, Medendorp SV, Becker M, Pimentel R, Gitlin L and Adelstein DJ: Endoscopic ultrasound cannot determine suitability for esophagectomy after aggressive chemoradiotherapy for esophageal cancer. Am J Gastroenterol 94: 906-912, 1999.

7. Tomizawa Y and Wang KK: Screening, surveillance, and prevention for esophageal cancer. Gastroenterol Clin North Am 38: 59-73, viii, 2009.

8. Kato H, Kuwano H, Nakajima M, Miyazaki T, Yoshikawa M, Ojima H, Tsukada K, Oriuchi N, Inoue T and Endo K: Comparison between positron emission tomography and computed tomography in the use of the assessment of esophageal carcinoma. Cancer 94: 921-928, 2002.

9. Sakai NS, Samia-Aly E, Barbera M and Fitzgerald RC: A review of the current understanding and clinical utility of miRNAs in esophageal cancer. Semin Cancer Biol 23: 512-521, 2013. 
10. Calin GA and Croce CM: MicroRNA signatures in human cancers. Nat Rev Cancer 6: 857-866, 2006.

11. Yates LA, Norbury CJ and Gilbert RJ: The long and short of microRNA. Cell 153: 516-519, 2013.

12. Kozomara A and Griffiths-Jones S: miRBase: Annotating high confidence microRNAs using deep sequencing data. Nucleic Acids Res 42 (Database Issue): D68-D73, 2014.

13. Calin GA, Sevignani C, Dumitru CD, Hyslop T, Noch E, Yendamuri S, Shimizu M, Rattan S, Bullrich F, Negrini M and Croce CM: Human microRNA genes are frequently located at fragile sites and genomic regions involved in cancers. Proc Nat Acad Sci USA 101: 2999-3004, 2004.

14. Krol J, Loedige I and Filipowicz W: The widespread regulation of microRNA biogenesis, function and decay. Nat Rev Genet 11: 597-610, 2010

15. Volinia S, Calin GA, Liu CG, Ambs S, Cimmino A, Petrocca F, Visone R, Iorio M, Roldo C, Ferracin M, et al: A microRNA expression signature of human solid tumors defines cancer gene targets. Proc Natl Acad Sci USA 103: 2257-2261, 2006.

16. Bartel DP: MicroRNAs: Genomics, biogenesis, mechanism, and function. Cell 116: 281-297, 2004.

17. Griffiths-Jones S, Grocock RJ, van Dongen S, Bateman A and Enright AJ: miRBase: microRNA sequences, targets and gene nomenclature. Nucleic Acids Res 34 (Database Issue): D140-D144, 2006.

18. Kroh EM, Parkin RK, Mitchell PS and Tewari M: Analysis of circulating microRNA biomarkers in plasma and serum using quantitative reverse transcription-PCR (qRT-PCR). Methods 50: 298-301, 2010

19. Ali S, Almhanna K, Chen W, Philip PA and Sarkar FH: Differentially expressed miRNAs in the plasma may provide a molecular signature for aggressive pancreatic cancer. Am J Transl Res 3: 28-47, 2010

20. Wang B and Zhang Q: The expression and clinical significance of circulating microRNA-21 in serum of five solid tumors. J Cancer Res Clin Oncol 138: 1659-1666, 2012.

21. Chen X, Ba Y, Ma L, Cai X, Yin Y, Wang K, Guo J, Zhang Y, Chen J, Guo X, et al: Characterization of microRNAs in serum: A novel class of biomarkers for diagnosis of cancer and other diseases. Cell Res 18: 997-1006, 2008.

22. Lu J, Getz G, Miska EA, Alvarez-Saavedra E, Lamb J, Peck D, Sweet-Cordero A, Ebert BL, Mak RH, Ferrando AA, et al: MicroRNA expression profiles classify human cancers. Nature 435: 834-838, 2005.

23. Fassan M, Baffa R, Kiss A, Zaninotto G and Rugge M: MicroRNA dysregulation in esophageal neoplasia: The biological rationale for novel therapeutic options. Curr Pharm Des 19: 1236-1241, 2013.

24. Redova M, Sana J and Slaby O: Circulating miRNAs as new blood-based biomarkers for solid cancers. Future Oncol 9: 387-402, 2013

25. Edge SB and Compton CC: The American Joint Committee on Cancer: The 7th edition of the AJCC cancer staging manual and the future of TNM. Ann Surg Oncol 17: 1471-1474, 2010.

26. Liu SG, Qin XG, Zhao BS, Qi B, Yao WJ, Wang TY, Li HC and $\mathrm{Wu} \mathrm{XN}$ : Differential expression of miRNAs in esophageal cancer tissue. Oncol Lett 5: 1639-1642, 2013.

27. Gilson PR and McFadden GI: The miniaturized nuclear genome of a eukaryotic endosymbiont contains genes that overlap, genes that are cotranscribed, and the smallest known spliceosomal introns. Proc Natl Acad Sci USA 93: 7737-7742, 1996.

28. Livak KJ and Schmittgen TD: Analysis of relative gene expression data using real-time quantitative PCR and the 2(-Delta Delta C(T)) method. Methods 25: 402-408, 2001

29. Schmittgen TD, Jiang J, Liu Q and Yang L: A high-throughput method to monitor the expression of microRNA precursors Nucleic Acids Res 32: e43, 2004.

30. MacCallum RC, Zhang S, Preacher KJ and Rucker DD: On the practice of dichotomization of quantitative variables. Psychol Methods 7: 19-40, 2002.

31. Hand DJ and Till RJ: A simple generalisation of the area under the ROC curve for multiple class classification problems. Mach Learn 45: 171-186, 2001.

32. Schisterman EF, Perkins NJ, Liu A and Bondell H: Optimal cut-point and its corresponding Youden Index to discriminate individuals using pooled blood samples. Epidemiology 16: 73-81, 2005 .
33. Akobeng AK: Understanding diagnostic tests 3: Receiver operating characteristic curves. Acta Paediatr 96: 644-647, 2007.

34. Yang LH, Wang SL, Tang LL, Liu B, Ye WL, Wang LL, Wang ZY, Zhou MT and Chen BC: Universal stem-loop primer method for screening and quantification of microRNA. PLoS One 9: e115293, 2014.

35. Chen C, Ridzon DA, Broomer AJ, Zhou Z, Lee DH, Nguyen JT, Barbisin M, Xu NL, Mahuvakar VR, Andersen MR, et al: Real-time quantification of microRNAs by stem-loop RT-PCR Nucleic Acids Res 33: e179, 2005.

36. Schmittgen TD, Zakrajsek BA, Mills AG, Gorn V, Singer MJ and Reed MW: Quantitative reverse transcription-polymerase chain reaction to study mRNA decay: Comparison of endpoint and real-time methods. Anal Biochem 285: 194-204, 2000.

37. Yin JL, Shackel NA, Zekry A, McGuinness PH, Richards C, Putten KV, McCaughan GW, Eris JM and Bishop GA: Real-time reverse transcriptase-polymerase chain reaction (RT-PCR) for measurement of cytokine and growth factor mRNA expression with fluorogenic probes or SYBR Green I. Immunol Cell Biol 79: 213-221, 2001

38. Asangani IA, Rasheed SA, Nikolova DA, Leupold JH, Colburn NH, Post S and Allgayer H: MicroRNA-21 (miR-21) post-transcriptionally downregulates tumor suppressor Pdcd4 and stimulates invasion, intravasation and metastasis in colorectal cancer. Oncogene 27: 2128-2136, 2008.

39. Meng F, Henson R, Wehbe-Janek H, Ghoshal K, Jacob ST and Patel T: MicroRNA-21 regulates expression of the PTEN tumor suppressor gene in human hepatocellular cancer. Gastroenterology 133: 647-658, 2007.

40. Zhu S, Si ML, Wu H and Mo YY: MicroRNA-21 targets the tumor suppressor gene tropomyosin 1 (TPM1). J Biol Chem 282: 14328-14336, 2007.

41. Kuhn AR, Schlauch K, Lao R, Halayko AJ, Gerthoffer WT and Singer CA: MicroRNA expression in human airway smooth muscle cells: Role of miR-25 in regulation of airway smooth muscle phenotype. Am J Respir Cell Mol Biol 42: 506-513, 2010.

42. Zhang H, Zuo Z, Lu X, Wang L, Wang H and Zhu Z: MiR-25 regulates apoptosis by targeting Bim in human ovarian cancer. Oncol Rep 27: 594-598, 2012

43. Liu R, Liao J, Yang M, Sheng J, Yang H, Wang Y, Pan E, Guo W, $\mathrm{Pu}$ Y, Kim SJ and Yin L: The cluster of miR-143 and miR-145 affects the risk for esophageal squamous cell carcinoma through co-regulating fascin homolog 1. PLoS One 7: e33987, 2012.

44. Furuta M, Kozaki KI, Tanaka S, Arii S, Imoto I and Inazawa J: miR-124 and miR-203 are epigenetically silenced tumor-suppressive microRNAs in hepatocellular carcinoma. Carcinogenesis 31: 766-776, 2010.

45. Yuan Y, Zeng ZY, Liu XH, Gong DJ, Tao J, Cheng HZ and Huang SD: MicroRNA-203 inhibits cell proliferation by repressing $\triangle \mathrm{Np} 63$ expression in human esophageal squamous cell carcinoma. BMC Cancer 11: 57, 2011.

46. Engell HC: CCancer cells in the circulating blood; a clinical study on the occurrence of cancer cells in the peripheral blood and in venous blood draining the tumour area at operation. Acta Chir Scand Suppl 201: 1-70, 1955.

47. Okumura Y, Tanaka F, Yoneda K, Hashimoto M, Takuwa T, Kondo $\mathrm{N}$ and Hasegawa S: Circulating tumor cells in pulmonary venous blood of primary lung cancer patients. Ann Thorac Surg 87: 1669-1675, 2009

48. Cristofanilli M, Budd GT, Ellis MJ, Stopeck A, Matera J, Miller MC, Reuben JM, Doyle GV, Allard WJ, Terstappen LW and Hayes DF: Circulating tumor cells, disease progression, and survival in metastatic breast cancer. N Engl J Med 351: 781-791, 2004.

49. Zhuang LP and Meng ZQ: Serum miR-224 reflects stage of hepatocellular carcinoma and predicts survival. Biomed Res Int 2015: 731781, 2015

50. Agrawal N, Jiao Y, Bettegowda C, Hutfless SM, Wang Y, David S, Cheng Y, Twaddell WS, Latt NL, Shin EJ, et al: Comparative genomic analysis of esophageal adenocarcinoma and squamous cell carcinoma. Cancer Discov 2: 899-905, 2012.

51. Barbash S, Shifman S and Soreq H: Global coevolution of human microRNAs and their target genes. Mol Biol Evol 31: 1237-1247, 2014. 